\title{
Relative growth of chela of the Japanese mitten crab Eriocheir japonica (De Haan) during the juvenile stages
}

\section{Satoshi Kobayashi and Shuhei Matsuura}

Abstract. - Relative growth of the chelae of the Japanese mitten crab Eriocheir japonica during the juvenile stages was investigated by laboratory rearing. Regression of chela propodus height (CPH) on carapace width (CW) suggested that two growth phases are present in juveniles ( $\mathrm{CW}<40 \mathrm{~mm}$ ) of both sexes. These two phases are separated by an inflection at approximately $11 \mathrm{~mm} \mathrm{CW}$ in both sexes. Between the first and second phases, there are significant differences in the slope and Y-intercept of the regression lines for each sex. Significant differences between sexes were not detected for the first phase, but were detected for the second phase. With the addition of data for sub-adult and adult stages a complete growth pattern of $E$. japonica chela could be estimated. In addition to the first phase three other phases in the males and two phases in females were observed.

\section{Introduction}

The Japanese mitten crab Eriocheir japonica (De Haan) is a catadromous brachyuran distributed in rivers and shallow seas throughout Japan, Sakhalien, east Korea and Taiwan (Sakai, 1976). This crab is homochelous and mature crabs have thick soft hair on their chelae, giving the English name of "mitten crab". We have already described the relative growth pattern of the chela in this species and found clear sexual dimorphism (Kobayashi \& Matsuura, 1993). Chelae of males are larger than those of the females, and the area occupied by the hair is greater in males than in females (Kobayashi \& Matsuura, 1993). However, the data used in this study was reliable only for larger juvenile and adult sizes [> $20 \mathrm{~mm}$ carapace width $(\mathrm{CW})]$, and it is necessary to reexamine the smaller sizes ( $<10 \mathrm{~mm} \mathrm{CW}$ ) for the following reasons. Crabs collected in the field were $>5 \mathrm{~mm}$ CW, but the first instar crabs of $E$. japonica are approximately $2 \mathrm{~mm} \mathrm{CW}$ (Morita, 1974). Therefore, data for crabs < $5 \mathrm{~mm} \mathrm{CW}$ are lacking. Small crabs, just after settlement, tend to moult frequently, each moult having small size increments (Morita, 1974). Thus, a change of growth pattern may occur during the repeated moults, and the growth pattern for smaller individuals may be different from that for larger sizes. Kobayashi \& Matsuura (1993) measured the carapace width and chela propodus height using vernier calipers to the nearest $0.1 \mathrm{~mm}$, so that significant figures were three for large juveniles and adult sizes (e.g., 10.0-86.0 mm) but only two for small juveniles (e.g., 5.2$9.9 \mathrm{~mm}$ ). Thus, values tend to be not as precise for small juveniles, with the possibility of error in measuring increases of smaller sizes. The data from small juveniles $<35 \mathrm{~mm} \mathrm{CW}$ were gathered into a single phase in each sex, but additional phases may be apparent and evident by adding data precisely measured for smaller sizes.

Many studies on relative growth of chela have been carried out in the study of brachyuran crabs with reference to the 


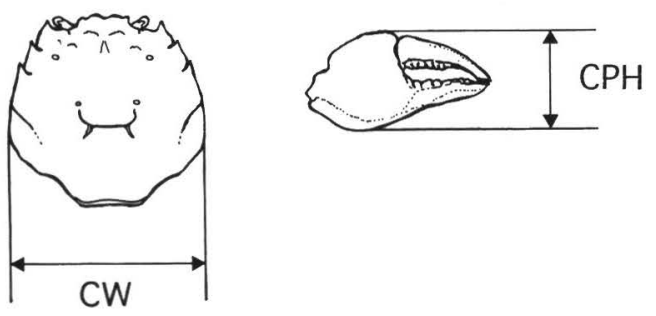

Fig.1. Positions of Eriocheir japonica measurements: CW, carapace width; $\mathrm{CPH}$, chela propodus height.

size of sexual maturity. Marked changes in growth of the chela size as a secondary sexual character is used to estimate the size of maturity (Hartnoll, 1974, 1978, 1982). However, precise measurement and division of phases in the juvenile (immature) stage tend to be ignored. In order to understand the detailed characteristics of growth within each species, it is necessary to investigate the complete growth pattern precisely.

In the present paper, we investigate the relative growth of chela in the juvenile stage using data precisely measured from crabs hatched and reared in the laboratory.

\section{Materials and Methods}

Brood stock were collected at the Tsuyazaki Beach, Munakata County, Fukuoka Prefecture, Japan $\left(33^{\circ} 47^{\prime} \mathrm{N}\right.$, $130^{\circ} 28^{\prime} \mathrm{E}$ ) and reared in the Kyushu University Fishery Research Laboratory in Tsuyazaki from September 1990 to July 1992 (see Kobayashi \& Matsuura, 1995a). Hatched larvae were reared in sea water and fed Artemia eggs and nauplii and after settlement (metamorphosing to the first instar crab), they were transferred to fresh water. Young crabs were then transferred to the Laboratory of Marine Biology, Kyushu University in Fukuoka City, Fukuoka Prefecture. They were individually reared from November 1990 to November 1994 . Water temperature was maintained consistently at $24-26{ }^{\circ} \mathrm{C}$ and the light condition was $24 \mathrm{~L}$. The size of aquaria was changed from $200 \mathrm{~cm}^{3}$ to $400 \mathrm{~cm}^{3}, 800 \mathrm{~cm}^{3}, 2000 \mathrm{~cm}^{3}$, as crabs grew. Sand and gravel, as bottom sediments, and a polyvinyl chloride pipe was provided for shelter in each aquarium. Freshwater green algae, wheat, fish meat and amphipods were supplied as food. Water was changed every one or two days. Exuvia of the crabs were used for measurements. For crabs $\leq 10 \mathrm{~mm} \mathrm{CW}$, the carapace width and chela propodus height (CPH) (Fig. 1) was measured by ruler from a magnified image to the nearest $0.01 \mathrm{~mm}$ using a profile projector. Vernier calipers were used to measure to the nearest $0.1 \mathrm{~mm}$ for individuals $10 \mathrm{~mm} \leq$ $\mathrm{CW}$. Values measured on the same samples of crabs around $10 \mathrm{~mm} \mathrm{CW}$ were not different between the two methods ( $<$ $0.1 \mathrm{~mm}$ ). Crabs were sexed from abdomen morphologies (Okada \& Miyashita, 1935). The sex of small individuals was assessed once individuals reached larger sizes.

\section{Results}

Fifteen male and 20 female juvenile crabs were reared in the laboratory, resulting in 98 male exuviae (1.91-33.9 mm $\mathrm{CW})$ and 104 female specimens (1.70-32.5 $\mathrm{mm} \mathrm{CW}$ ) for measurements.

Figure 2 shows the relationship between carapace width (CW) and chela propodus height (CPH). From the distribution pattern of the data, the presence of two linear growth phases, divided at an inflection point, is suggested in both sexes. The size at the inflection point occurs at approximately $11 \mathrm{~mm}$ CW in both sexes. Equations and regression lines for each phase on a natural logarithmic scale are shown in Fig. 3. All the regression lines were significant (F-test, $P<0.01$ ). To compare the growth patterns between the different CW ranges of the same sex and between sexes lines were compared by analysis of covariance (Table 1). In both 


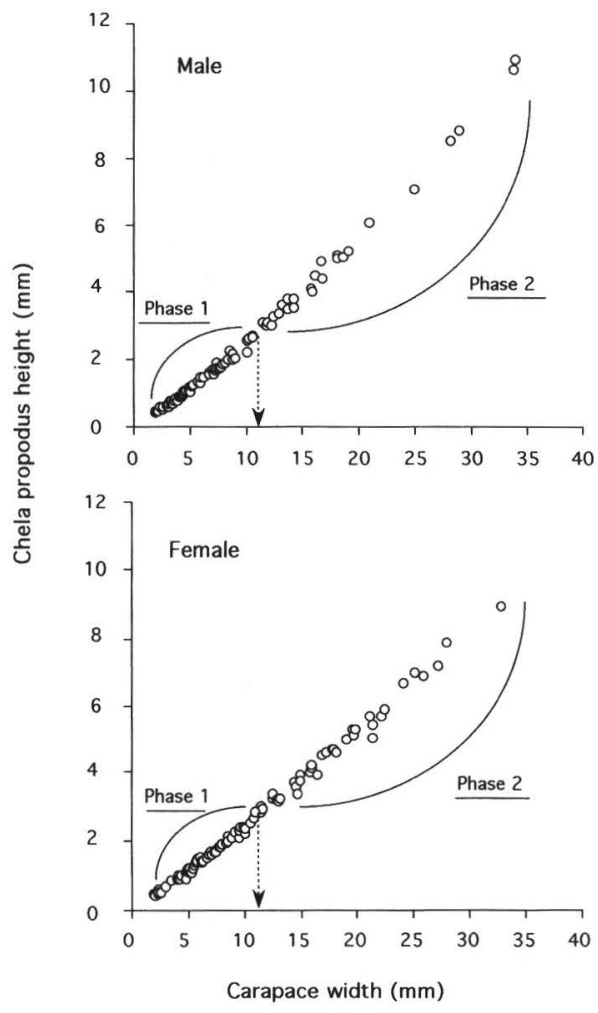

Fig. 2. The relationship between chela propodus height and carapace width of juvenile Eriocheir japonica. Axes are linear; Phase 1 and Phase 2 were divided by the distribution of dots.

sexes, there were significant differences between the first and second phases in both the slope and the Y-intercept. Between sexes, a significant difference did not occur for the first phase, but was present between the second phase in both slope and the Y-intercept (Table 1).

\section{Discussion}

Data presented here, indicate that there is an additional growth phase in the E. japonica juvenile stage. This phase was present at $\mathrm{CW}<11 \mathrm{~mm}$, with no significant difference in growth pattern between males and females. Thus, $E$. japonica have a growth phase with no

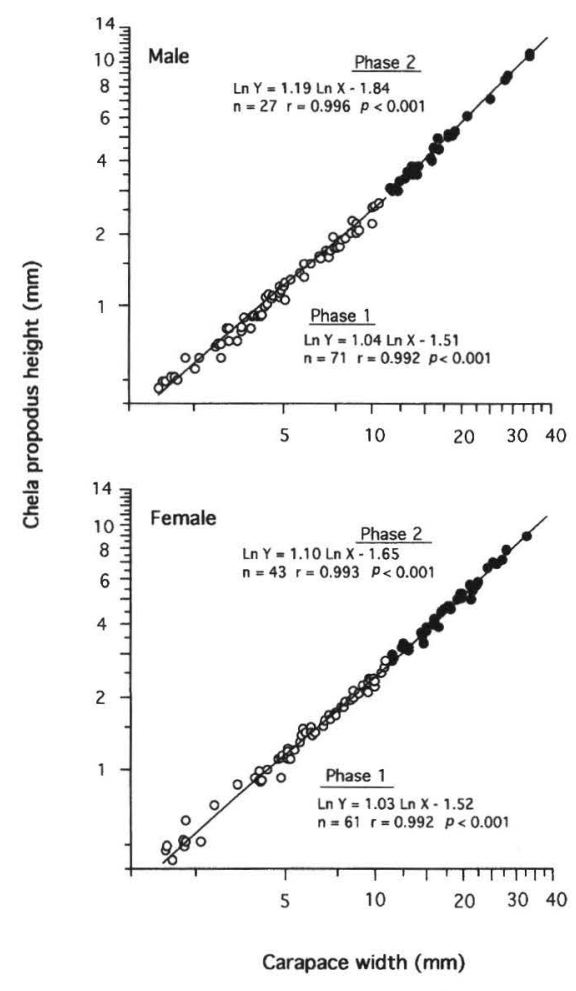

Fig. 3. Regression lines for the chela propodus height relative to carapace width of juvenile Eriocheir japonica. Axes are natural logarithms.

difference in secondary sexual characteristics up to $11 \mathrm{~mm}$ in CW. Secondary sexual characteristics become evident in the following growth phases.

We have already reported the presence of three phases in the male, and two phases in the female, among sub-adult and adult sized crabs collected in Kagoshima Prefecture (Kobayashi \& Matsuura, 1993). If we suppose that the growth patterns of crabs both in Kagoshima Prefecture and Fukuoka Prefecture are similar, because the CW-size distributions of mature crabs in these areas were similar (Kobayashi \& Matsuura, $1995 \mathrm{a}, 1995 \mathrm{~b})$, the complete allometric 
Table 1. Results of analysis of covariance between growth phase regression lines of Eriocheir japonica.

\begin{tabular}{ccc}
\hline \hline & $F$-value & $P$ \\
\hline $\begin{array}{c}\text { Male-Male } \\
\text { phase 1, phase 2 }\end{array}$ & & \\
slope & 8.55 & $<0.01$ \\
Y-intercept & 9.43 & $<0.01$ \\
$\begin{array}{c}\text { Female-Female } \\
\text { phase 1, phase 2 }\end{array}$ & & \\
slope & 4.24 & $<0.05$ \\
Y-intercept & 6.25 & $<0.05$ \\
Male-Female & & \\
phase 1, phase 1 & & \\
slope & 0.54 & $>0.05$ \\
Y-intercept & 0.83 & $>0.05$ \\
phase 2, phase 2 & 6.09 & $<0.05$ \\
slope & 67.41 & $<0.001$ \\
Y-intercept & 37 &
\end{tabular}

growth pattern of chela in $E$. japonica can be estimated by adding the present results to the data of Kobayashi \& Matsuura (1993). The estimated growth pattern of $E$. japonica is given in Fig. 4. Four phases are present in males, which are divided by inflections (between the first and the second phases and between the second and the third phases) and a discontinuity (between the third and the fourth phases). In females, three phases are present. Inflections occur at approximately $11 \mathrm{~mm}$ and $35 \mathrm{~mm} \mathrm{CW}$, in both sexes. A discontinuity occurs between 50 $\mathrm{mm}$ and $65 \mathrm{~mm} \mathrm{CW}$ in males. Sexual difference in the allometric growth pattern is absent in the first phase, but it becomes more noticeable in the second to fourth phases. Sexually mature crabs occurred

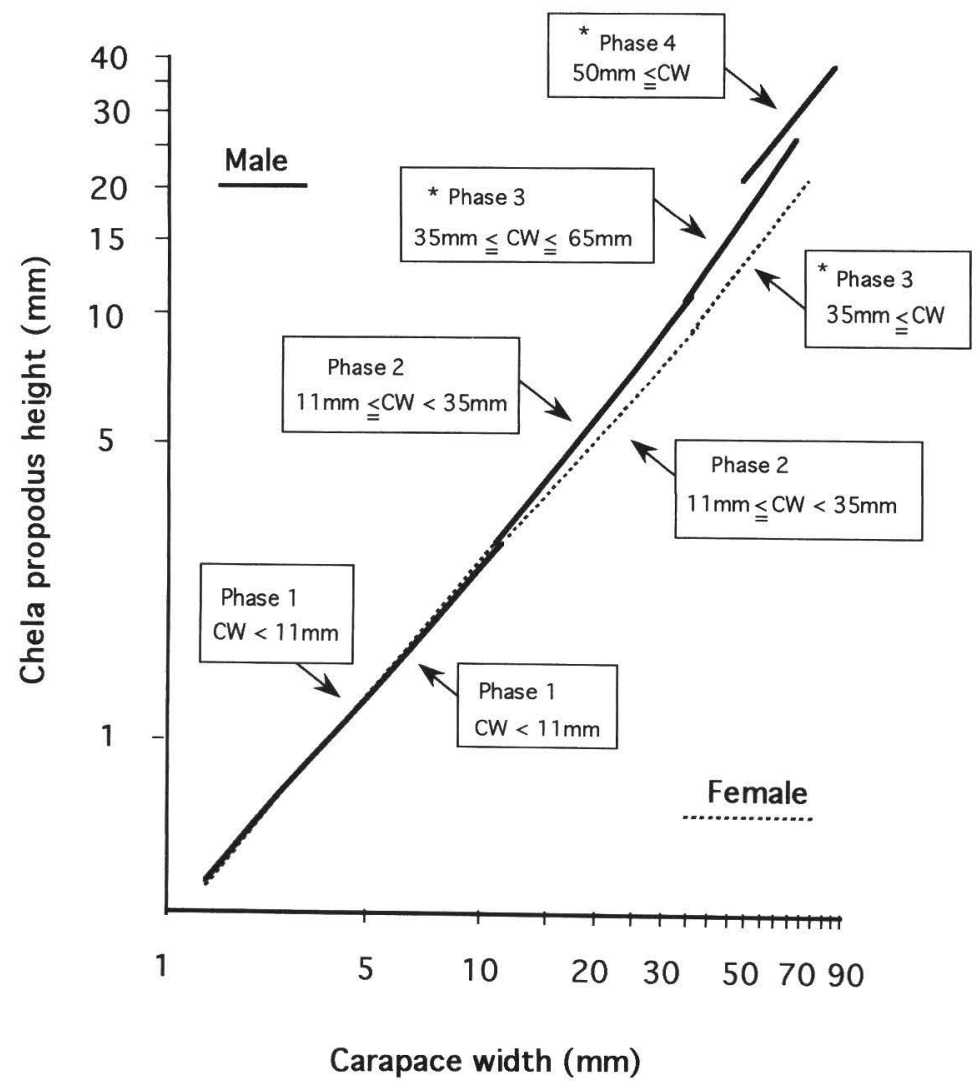

Fig. 4. Estimated complete growth pattern of the chela of Eriocheir japonica. Asterisks indicate the occurrence of sexually mature crabs. 
in the third and fourth phases in males, and the third phase in females $[36 \mathrm{~mm}<$ $\mathrm{CW}<86 \mathrm{~mm}$ in the male, and $36 \mathrm{~mm}<$ CW $<75 \mathrm{~mm}$ in the female (Kobayashi \& Matsuura, 1995b)].

The growth pattern of soft hair on the chelae also indicated the division of these phases. We have already described the occurrence of five stages of hair-distribution on the chelae (Kobayashi \& Matsuura, 1993). In stage I, hair is only sparsely distributed and fine. In stage II, the hair is densely distributed, but only on the outer lateral side of the propodus and dactylus. In stages III, IV and V, the hairy area spreads to the inner lateral side. In stage III, the hair spreads only to the area around the attachment of the dactylus. In stage IV, the hairy area spreads to the central part of the inner lateral side of the propodus. In stage V, a hairy tuft occurs on the dorsal side, with most of the surface area of the propodus and dactylus being covered (Kobayashi \& Matsuura, 1993). The occurrence of individuals in each stage showed that the hairy area increased with $\mathrm{CW}$ and $\mathrm{CPH}$ in both sexes. In males, stage I occurs at $\mathrm{CW} \leq 10 \mathrm{~mm}$, stage II between $9 \mathrm{~mm} \leq \mathrm{CW} \leq 35 \mathrm{~mm}$, stage III between $38 \leq \mathrm{CW} \leq 45 \mathrm{~mm}$, stage IV between $46 \mathrm{~mm} \leq \mathrm{CW} \leq 60 \mathrm{~mm}$, and stage $\mathrm{V}$ at $50 \mathrm{~mm} \leq \mathrm{CW}$. For females, stage I occurs at $\mathrm{CW} \leq 10 \mathrm{~mm}$, stage II between $10 \mathrm{~mm} \leq \mathrm{CW} \leq 45 \mathrm{~mm}$, and stage III at $50 \mathrm{~mm} \leq \mathrm{CW}$ (Kobayashi \& Matsuura,1993). Thus, the divisions of the phases in relative growth in the present study (Fig. 4) closely correlate with the occurrence of the stages of the soft-hair (Table 2). Phases 1 and 2 correspond to stages I and II, respectively in both sexes. In males phase 3 corresponds to stages III and IV and phase 4 corresponds to stage V. As for females, phase 3 corresponds to stages II and III.

The size or stage of sexual differentiation in other sexual characteristics (primary sexual characteristics) have been reported in $E$. japonica. Morita (1974) de-
Table 2. Stages of soft-hair distribution on Eriocheir japonica chelae corresponding to the phases of allometric growth pattern of chelae.

\begin{tabular}{lcc}
\hline \hline & Male & Female \\
\hline Phase 1 $^{1)}$ & Stage I & Stage I \\
Phase 2 & Stage II & Stage II \\
Phase 3 & Stages III \& IV & Stages II \& III \\
Phase 4 & Stage V & \\
\hline
\end{tabular}

1) See Fig. 4 for the size range and growth pattern of each phase.

${ }^{2)}$ See Kobayashi \& Matsuura (1993) for the characteristics of each stage.

scribed sexual differentiation in the pleopods which becomes evident after the fourth instar crab stage, and Lee et al. (1994) found differentiation at the third instar. CW of the third and fourth instar crabs are around $4.3 \mathrm{~mm}$ and $5.5 \mathrm{~mm}$ (Morita, 1974). However, gender can be determined as early as the megalopal stage on the basis of the different orientation of the gonoducts (Lee et al.,1994). The sexual difference in chela size is not evident until $11.0 \mathrm{~mm} \mathrm{CW}$ (present study). Crabs of approximately $11.0 \mathrm{~mm} \mathrm{CW}$ are in the eighth to tenth instar $(n=6$, Kobayashi \& Matsuura, unpublished data). This suggests that the secondary sexual characteristics of the chela in relation to size become evident several instars later than the primary sexual characteristics.

Ecological studies on some species of intertidal crabs (ocypodids and grapsids) have revealed the presence of unsexable phases among smaller crabs just after settlement, e.g., Scopimera globosa and Ilyoplax pusillus (Wada, 1981); Hemigrapsus sanguineus, $H$. penicillatus, Gaetice depressus, Acmaeopleura parvula, Nanosesarma gordoni and Cyclograpsus intermedius (Fukui, 1988). Although sex was determined, not by chela size but by abdominal morphology, the phase which is unsexable using secondary sexual characters may be present in many brachyuran species. 


\section{Acknowledgments}

We wish to thank the members of the Laboratory of Marine Biology, Kyushu University, for their kind assistance and Dr. C. L. McLay of the University of Canterbury for reviewing the manuscript.

\section{Literature Cited}

Fukui, Y., 1988. Comparative studies on the life history of the grapsid crabs (Crustacea, Brachyura) inhabiting intertidal cobble and boulder shores. Publications of the Seto Marine Biological Laboratory, 33: 121-162.

Hartnoll, R. G., 1974. Variation in growth pattern between some secondary characters in crabs (Decapoda Brachyura). Crustaceana, 27: 131-136.

$\longrightarrow$, 1978. The determination of relative growth in Crustacea. Crustaceana, 34: 281-293.

- 1982. Growth. In: L. G. Abelle (ed.), The Biology of Crustacea, vol.2, pp.111196, Academic Press, New York.

Kobayashi, S. \& Matsuura, S., 1993. Ecological studies on the Japanese mitten crab Eriocheir japonicus De Haan - III. Relative growth of the chela and soft-hair distribution on the chela. Benthos Research, 45: 19.

, \& — 1995a. Reproductive ecology of the Japanese mitten crab Eriocheir japonicus (De Haan) in its marine phase. Benthos Research, 49: 15-28.

,$\&-, 1995 \mathrm{~b}$. Population structure of the Japanese mitten crab Eriocheir japonicus (De Haan) - clinal variation in size of maturity. Crustacean Research, 24: 128-136.

Lee, T., Yamauchi, M., \& Yamazaki, F., 1994. Sex differentiation in the crab Eriocheir japonicus (Decapoda, Grapsidae). Invertebrate Reproduction and Development, 25: 123-138.

Morita, T., 1974. Morphological observation on the development of larva of Eriocheir japonica De Haan. Zoological Magazine, 83: 24-81.(In Japanese with English summary)

Okada, Y. K., \& Miyashita, Y., 1935. Sacculinization in Eriocheir japonicus de Haan, with remarks on the occurrence of complete sex-reversal in parasitized male crabs. Memoirs of the College of Science, Kyoto Imperial University, Series B, 10: 169-208.

Sakai, T., 1976. Crabs of Japan and adjacent seas. Kodansha, Tokyo. [In 3 volumes: (1) English text, xxix + 773pp. (2) Plates volume, 16pp., 251pls. (3) Japanese text, 461pp.].

Wada, K., 1981. Growth, breeding, and recruitment in Scopimera globosa and Ilyoplax pusillus (Crustacea: Ocypodidae) in the estuary of Waka River, middle Japan. Publications of the Seto Marine Biological Laboratory, 26: 243-259.

Address: Department of Fisheries, Faculty of Agriculture, Kyushu University, Hakozaki, Higashi, Fukuoka 812, Japan.

E-mails: (SK) s_kobaya@agr.kyushu-u.ac. jp; (SM) matsuura@agr.kyushu-u.ac.jp 